\title{
Application of the Geostationary Ocean Color Imager to Mapping the Diurnal and Seasonal Variability of Surface Suspended Matter in a Macro-Tidal Estuary
}

\author{
Zhixin Cheng ${ }^{1,2, *}$, Xiao Hua Wang ${ }^{1,2}$, David Paull ${ }^{2}$ and Jianhua Gao ${ }^{3}$ \\ 1 The Sino-Australian Research Centre for Coastal Management, University of New South Wales, \\ Canberra, BC 2610, Australia; X.Wang@adfa.edu.au \\ 2 School of Physical, Environmental and Mathematical Sciences, University of New South Wales, \\ Canberra, BC 2610, Australia; D.Paull@adfa.edu.au \\ 3 Key Laboratory of Coast and Island Development, Nanjing University, Ministry of Education, \\ Nanjing 210093, China; jhgao@nju.edu.cn \\ * Correspondence: Zhixin.Cheng@student.adfa.edu.au; Tel.: +61-45-6308-574
}

Academic Editors: Deepak R. Mishra, Richard W. Gould, Xiaofeng Li and Prasad S. Thenkabail Received: 16 December 2015; Accepted: 4 March 2016; Published: 15 March 2016

\begin{abstract}
Total suspended particulate matter (TSM) in estuarine and coastal regions usually exhibits significant natural variations. The understanding of such variations is of great significance in coastal waters. The aim of this study is to investigate and assess the diurnal and seasonal variations of surface TSM distribution and its mechanisms in coastal waters based on Geostationary Ocean Color Imager (GOCI) data. As a case study, dynamic variations of TSM in the macro-tidal Yalu River estuary (YRE) of China were analysed. With regard to diurnal variability, there were usually two peaks of TSM in a tidal cycle corresponding to the maximum flood and ebb current. Tidal action appears to play a vital role in diurnal variations of TSM. Both the processes of tidal re-suspension and advection could be identified; however, the diurnal variation of TSM was mainly affected by a re-suspension process. In addition, spring-neap tides can affect the magnitude of TSM diurnal variations in the YRE. The GOCI-retrieved TSM results clearly showed the seasonal variability of surface TSM in this area, with the highest level occurring in winter and the lowest in summer. Moreover, although river discharge to the YRE was much greater in the wet season than the dry season, TSM concentrations were significantly higher in the dry season. Wind waves were considered to be the main factor affecting TSM seasonal variation in the YRE.
\end{abstract}

Keywords: geostationary ocean colour remote sensing; suspended particulate matter; seasonal variation; diurnal dynamics

\section{Introduction}

Estuaries are vital links between catchments and coastal waters; they contain high concentrations of total suspended particulate matter (TSM) and are characterized by complicated hydrodynamics and environmental systems affected simultaneously by physical, biogeochemical and human activities. Estuaries, therefore, are amongst the most complicated of natural systems [1]. Sea surface TSM exhibits significant diurnal and seasonal variability in estuarine regions that can influence the available light underwater and affect the productivity of upper-layer phytoplankton [2,3]. In addition, sedimentary processes in coastal waters can provide nutrients to neighbouring sea areas and affect the transport of carbon, pollutants and other materials [4-6]. Thus, monitoring dynamic variations of surface TSM concentrations in estuaries is of great significance, as it can provide a key to understanding sedimentary processes in coastal waters. 
Systematically mapping TSM in coastal waters based on direct field measurements is difficult due to large variations of sediment across both spatial and temporal scales. Over recent decades, with the introduction of ocean satellite sensors, TSM concentrations have been mapped in coastal waters throughout the world using ocean colour remote sensing techniques [3,7-11]. However, most of the well-known ocean colour sensors, such as the Sea-viewing Wide Field-of-view Sensor (SeaWiFS), Moderate Resolution Imaging Spectroradiometer (MODIS) and Medium Resolution Imaging Spectrometer (MERIS), are carried on polar-orbiting satellites, which can only measure a place one time per day in low-mid latitude regions. Accordingly, although data observed by these polar-orbiting satellites can synoptically map surface TSM concentrations, they have insufficient temporal resolution to monitor diurnal variations of TSM in coastal waters.

The Geostationary Ocean Color Imager (GOCI), carried on COMS (Communication Ocean and Meteorological Satellite, which was launched on 26 June 2010 by South Korea, is capable of monitoring regional oceanic phenomena, such as tide dynamics, red tides, river plumes and sediment transport [12]. Compared with polar-orbiting satellites, GOCI uniquely enables the observation of marine environments across the northeast Asia region covering the coasts of Eastern China, the Korean Peninsula and Japan, along with their corresponding shelves and open oceans [13]. GOCI acquires data in eight spectral bands (six visible, two near infrared (NIR)) at a spatial resolution of $500 \mathrm{~m}$ and an imaging frequency of $1 \mathrm{~h}$ during daylight (00:30-07:30 GMT), yielding eight images per day [13]. These high spatial and temporal resolution observations greatly enhance the ability to assess environmental changes in both inland and coastal waters [13,14]. The GOCI data products include chlorophyll concentration, optical diffuse attenuation coefficients, absorption coefficient of dissolved organic material or "yellow substance" and the concentration of suspended particles in the near-surface zone of the sea [15].

The unprecedented high-frequency measurements of GOCI have not only increased cloud-free observations, but also provided data critical to understanding short-term ocean dynamics [16]. Preliminary studies have shown the potential of using GOCI data to study diurnal changes in suspended sediment, chlorophyll-a concentration, harmful algal blooms and surface currents $[12,15,17]$. Recent studies have attempted to use data from GOCI to map short-term dynamics of surface TSM concentrations, indicating the feasibility and advantages of this sensor for monitoring the diurnal variability of TSM in coastal waters $[2,4,18,19]$. However, the application of GOCI data to study both seasonal and diurnal variability of TSM in the Northern Yellow Sea has not been reported.

The present study took the Yalu River Estuary (YRE) as an example. Our aim was to investigate and assess seasonal and diurnal variations of the surface TSM distribution and its driving mechanisms in turbid coastal waters based on GOCI data. The YRE and adjacent coastal waters form a typical macro-tidal and well-mixed environment connecting the Yalu River and northern part of the Yellow Sea. Moreover, the combined hydrodynamics controlled by river discharge, wind waves and strong tidal action in the YRE cause the TSM distribution in this area to exhibit significant seasonal and diurnal variability $[20,21]$. Thus, these factors make the YRE ideal for testing the feasibility of using GOCI to investigate surface TSM concentrations and for studying the mechanisms that drive TSM dynamics in a medium-to-small-sized estuarine system.

The remainder of this paper is organized as follows: Section 2.1 introduces the hydrodynamic and meteorological conditions of the YRE; Sections 2.2-2.4 describe the datasets used in this study and explain the GOCI data processing procedure along with the TSM algorithm we used; Sections 3.1-3.4 describe the GOCI-derived TSM results at different time scales and discuss the factors affecting temporal variations of TSM in the YRE; and Section 4 presents our conclusions. 


\section{Data and Methods}

\subsection{Study Area}

The Yalu River is the major regional river that discharges into the Northern Yellow Sea (NYS) at the border between China and North Korea (Figure 1). It originates in Changbai Mountain and has a total length of $790 \mathrm{~km}$. The average annual discharge is about $2.5 \times 10^{10} \mathrm{~m}^{3} \cdot$ year $^{-1}$ (equating to $800 \mathrm{~m}^{3} \cdot \mathrm{s}^{-1}$ ), and the average annual sediment load is $1.6 \times 10^{6} \mathrm{t}$ [22]. The Yalu River drainage has a mid-latitude, continental, monsoon climate; with an annual mean temperature of $8^{\circ} \mathrm{C}$ and $881-1087 \mathrm{~mm}$ of rainfall per year. Summer (from June-August) contributes $65 \%$ of the total rainfall and $33 \%$ of the annual water discharge of the river [21]. The discharge of the Yalu River shows significant seasonal variability; the peak monthly averaged water discharge for August $\left(1461 \mathrm{~m}^{3} \cdot \mathrm{s}^{-1}\right)$ is about two times greater than April $\left(662 \mathrm{~m}^{3} \cdot \mathrm{s}^{-1}\right)$ [23]. As a consequence, sediment input by the river to the YRE is much greater in the wet season (June-September) than the dry season (December-April), with the wet season accounting for $72 \%-85.6 \%$ of the total annual discharge.

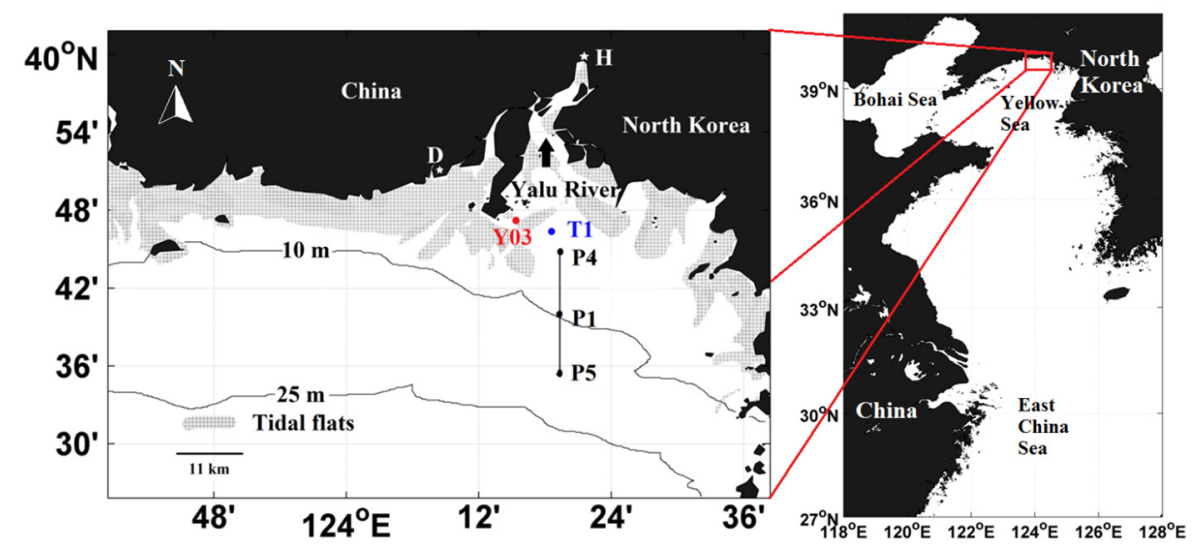

Figure 1. Location and bathymetry of the Yalu River estuary and its surrounding shelf region. Black points T1, P1, P4, P5 indicate selected monitoring stations. The line between P4 and P5 is the selected Section 1. D and H indicate the location of the Donggang Meteorological Station and Huanggou Hydrologic Station, respectively. Y03 is the location of the field observation station.

The hydrology of the estuarine area is complex and strongly influenced by not only river discharge, but wind waves and tidal currents. As a typical macro-tidal estuary, the YRE has a mean tidal range of $4.6 \mathrm{~m}$ and strong tidal currents (up to $1.5-2 \mathrm{~m} \cdot \mathrm{s}^{-1}$ ) dominated by semidiurnal tides [23]. Tides in the YRE are under the control of a standing-wave system in the Yellow Sea [23]; tidal current velocity can simply be considered to be slow at slack tides and fast at the midpoint between high and low water. Directions of flood and ebb currents in the YRE are basically perpendicular to the coast [20]. In addition, there is a significant diurnal inequality of tidal range in the YRE, and ebb tide lasts longer than flood tide in a tidal cycle [23]. Wave action at the entrance of the Yalu River is relatively weak, as the average significant wave height outside the estuary near the Donggang Oceanographic Station is $0.5 \mathrm{~m}[20]$.

The study area has a maximum water depth of $25 \mathrm{~m}$ with vast tidal flats near shore [24]. To quantify spatial and temporal variations of surface TSM, three points (P4, P1, P5) were selected from the north to the south of the YRE (Figure 1). Of the three points, P4 was positioned closest to the estuary at the limit of the data coverage of GOCI. A line connecting these three points, Section 1, was used to examine spatial trends in TSM. 


\subsection{GOCI Images}

GOCI Level-1B data were obtained from Korea Ocean Satellite Center (KOSC) for cloud-free or low cloud coverage days from 1 April 2011-31 December 2014. Hourly measurements every day from 8:28-15:28 local time at a frequency of $1 \mathrm{~h}$ in 2014 were used to study the natural variation of TSM in the YRE. Except for the winter season, the observing period of GOCI is under adequate solar illumination in the East China Seas [2]; thus, noise caused by viewing and illumination geometries was assumed to be negligible for this study. GOCI Level-1B data contain total radiance at the top of the atmosphere over all eight bands for each time observation. Radiometric and geometric corrections of GOCI Level-1B data had previously been performed using an automated preprocessing system [25]. The original algorithm GDPS first implemented in GDPS v1.0.0 was based on the algorithm established for SeaWiFS data by Gordan and Wang [26], which did not perform well in turbid water. Wang [27] put forward an improved atmospheric correction using a near-infrared algorithm for GOCI in the turbid western Pacific region, which performed well [28]. To improve the performance of the atmospheric correction algorithm in turbid waters, the MUMM algorithm developed by Ruddick [29] was implemented in the latest version of GDPS (v.1.3.0). This algorithm calculates the contribution of aerosols and water to satellite reflectance on a per-pixel basis, with the assumption of spatially-constant Band-7: Band- 8 ratios for aerosol reflectance $(\varepsilon)$ and water reflectance $(\alpha)$ at 2 near-infrared (NIR) bands [30]. The limitation of this algorithm is that remote sensing reflectance $\left(R_{\mathrm{rs}}\right)$ from extremely turbid water $\left(\operatorname{Rrs}(660) \geqslant 0.015 \mathrm{sr}^{-1}\right)$ can be underestimated due to the decrease of water reflectance after saturation by short wave lengths, as turbidity increases [27]. In order to avoid this underestimation, Ahn [30] used a modified version of this algorithm (m-MUMM algorithm) in which the alpha value changes in proportion to turbidity by iterated calculations. This m-MUMM algorithm implemented by the current version of GDPS (which is also the algorithm adopted by the present study) can be applied in coastal turbid waters. The validation of this algorithm was taken based on in situ $\mathrm{R}_{\mathrm{rs}}$ in 2012 (13 match-ups in total from the Mokpo coastal area, Korea) with the root mean square error (RMSE) for 8 bands of $0.0029,0.0026,0.0028,0.0027,0.0015,0.0016,0.0011$ and $0.0011 \mathrm{sr}^{-1}$, respectively [31].

The bi-directional effect of ocean reflectance has also been previously corrected by GDPS in the atmospheric correction process: to correct the bi-directional effect of ocean reflectance, GOCI defined angular functions as follows [31]:

$$
\begin{gathered}
\operatorname{Rrs}\left(\lambda, \theta_{s}, \theta_{v}, W\right)=\frac{\rho_{w n}(\lambda)}{\pi} \times \frac{\Re_{s}\left(\lambda, \theta_{s}=0, W\right)}{\Re_{s}\left(\lambda, \theta_{s}, W\right)} \times \frac{\Re_{v}\left(\lambda, \theta_{v}=0, W\right)}{\Re_{v}\left(\lambda, \theta_{v}, W\right)} \times \\
\frac{f\left(\lambda, \theta_{s}=0, \theta_{v}=0, \phi_{s-v}=0, I O P\right) Q\left(\lambda, \theta_{s}, \theta_{v}, \phi_{s-v}, I O P\right)^{\prime}}{Q\left(\lambda, \theta_{s}=0, \theta_{v}=0, \phi_{s-v}=0, I O P\right) f\left(\lambda, \theta_{s}, \theta_{v}, \phi_{s-v}, I O P\right)}
\end{gathered}
$$

where $\Re_{S}$ is the downward air-sea transmittance, $\Re_{v}$ is the upward sea-air transmittance, $Q / f$ represents the in-water bidirectional effect function and $W$ is wind $[32,33]$.

After evaluation, GOCI data for 79 days throughout 2014 that contained minimal cloud coverage were selected to study TSM diurnal variability in the YRE; among them, data on 30 May and 8 June 2014 were used to examine TSM distribution in neap and spring tides, while 3 April and 2 August 2014 were selected to characterize TSM variation in dry and wet seasons. Monthly mean TSM results in 2014 were average results of TSM maps at local time 12:28 and 13:28 (with reliable data coverage) on every cloud-free day in that month.

\subsection{In Situ Data}

Field data were obtained from the YRE in the wet season (August) of 2009. At an hourly basis over $25 \mathrm{~h}$, vertical profiles of temperature, salinity, turbidity, chlorophyll-a and dissolved oxygen at ship-based anchor station Y03 (Figure 1) were measured in spring tide (8-9 August) and neap tide (14-15 August), respectively. These in situ data were observed by using a multi-parameter water quality probe $\mathrm{YSI}^{\circledR} 6600$, which measures turbidity via an optical sensor. The output of the turbidity sensor was processed via the sonde software to provide readings in nephelometric turbidity units 
(NTUs). The International Standards Organization (ISO) recommends the use of a light source with a wavelength between 830 and $890 \mathrm{~nm}$ and a scattering angle of 90 degrees between the emitted and detected radiation for optically measuring turbidity, which is a standard met by the YSI ${ }^{\circledR} 6600$. Water samples at $Y 03$ were collected based on the "three points" method by a rosette Niskin sampler at the upper layer ( $0.5 \mathrm{~m}$ from the water surface), middle layer and bottom layer ( $0.5 \mathrm{~m}$ to the bottom) with a frequency of $1 \mathrm{~h}$ during the observing period. The weather during the observation period was fine with limited wind speed. Suspended solids were filtered by pre-weighed cellulose acetate membrane $0.45-\mu \mathrm{m}$ filters ( $47 \mathrm{~mm}$ diameter). The filters were first dried at $40{ }^{\circ} \mathrm{C}$ for $8 \mathrm{~h}$ in an oven and then placed in the silica gel drier for $8 \mathrm{~h}$. Finally, the suspended solids were weighed by using a balance with an accuracy of $0.0001 \mathrm{~g}$. To eliminate the effect of the impairment of filters, $10 \%$ of the water samples were filtered with double-layer filters. The measured turbidity was converted to TSM using the relationship established by TSM retrieved from hourly in situ filtered water samples.

The retrieved in situ TSM values were provided by Nanjing University, China, who also provided the relationship between turbidity and TSM at Y03 as $y=1.576 x-35.5$ for neap tide and $y=1.557 x-14.77$ for spring tide, where $\mathrm{x}$, y represent turbidity (NTU) and TSM $\left(\mathrm{g} \cdot \mathrm{m}^{-3}\right)$, respectively. The correlation coefficients for the relationships for neap tide and spring tide were 0.952 and 0.936 , respectively [34].

The TSM in the upper layer (water depth $<0.5 \mathrm{~m}$ ) at Y03 was obtained in this study to make a comparison with the surface GOCI-retrieved TSM concentration under similar tidal conditions. The hourly GOCI results at T1 (Figure 1) on 2 August 2014 (spring tide) and 7 August 2014 (neap tide) were selected to make the comparison. Here, the GOCI results at T1 were averaged values of a box with $5 \times 5$ pixels around T1.

In addition to field measurements, other data were obtained from several sources in this study. Monthly averaged water discharge and sediment load of the Yalu River from 2011-2014 were provided by the Huanggou Hydrological Station ( $\mathrm{H}$ in Figure 1). Statistical results of wave height and direction and data of wind speed and direction in 2014 from the Donggang Meteorological Station (D in Figure 1) were used to investigate possible mechanisms of seasonal TSM variation. Forecasted data of daily area-averaged wind speeds, $10 \mathrm{~m}$ above sea level, and corresponding significant wave height over the study area for the year 2014 from the European Centre for Medium-Range Weather Forecasts (ECMWF) with a spatial resolution of $0.125^{\circ} \times 0.125^{\circ}$ were also used to examine the controlling factors for TSM seasonal variation. Forecasted hourly tide heights were obtained from tide tables from Donggang Oceanographic Station to analyse the process of diurnal variability of TSM and the effects of different tidal ranges on TSM diurnal dynamics.

\subsection{Quantitative Retrieval Algorithm of TSM}

Advances have been made in numerous studies in the development of algorithms for suspended solids after the introduction of ocean colour sensors, such as Gordon's semi-analytical algorithm, logarithm algorithm, power exponential algorithm and synthetic algorithm [35-39].

Based on characteristics of GOCI bands, Yu [40] developed a new algorithm that is applicable for the Yellow Sea by carrying out parameter optimization and genetic programming as follows:

$$
\lg \mathrm{C}_{\mathrm{TSM}}=4.8581+0.8206 \times \frac{\mathrm{B} 7}{\mathrm{~B} 3}-0.9998 \times \frac{\mathrm{B} 4}{\mathrm{~B} 3}-3.6504 \times \sqrt{\frac{B 3}{B 5+B 4}}
$$

where $\mathrm{C}_{\text {TSM }}$ is surface TSM concentration in the ocean in $\mathrm{g} \cdot \mathrm{m}^{-3}$ and $\mathrm{B}$ represents the remote sensing reflectance $\left(R_{r s}\right)$ corresponding to the central wavelengths of 4 bands $(490 \mathrm{~nm}, 555 \mathrm{~nm}, 660 \mathrm{~nm}$ and $745 \mathrm{~nm}$ ). All parameters were derived by parameter optimization based on in situ data.

This regional algorithm was put forward using a genetic programming (GP) method, which can automatically generate a model according to an input dataset. A comparison between the results of this algorithm and results from other existing algorithms has been made using field measurements at 126 stations from cruises in 2005, 2006, 2007 and 2008 in the Bohai and Yellow Seas [40]. Equation (2) 
appeared to be the optimal algorithm for this region with the correlation coefficient and the RMSE being 0.9916 and $4.06 \mathrm{~g} \cdot \mathrm{m}^{-3}$, respectively [40]. Considering that this algorithm was established using vast field measurements in the Yellow Sea with good performance, it was adopted in the present study to retrieve the TSM concentration in the upper layer of the YRE and adjacent areas.

Direct validation of the above algorithm by in situ observation is problematic, as there were no field programs performed during the study period in the YRE. In order to achieve greater confidence about the TSM results, a comparison between the in situ surface TSM in August 2009 and the GOCI-retrieved TSM in August in the YRE was made using data under similar tidal conditions (Figure 2a). There were 16 pairs of comparisons in total. For the spring tide, the comparison was made over the period from $2 \mathrm{~h}$ after low slack water to $3 \mathrm{~h}$ after high slack water with an interval of $1 \mathrm{~h}$. For the neap tide, the comparison was made over the period from $3 \mathrm{~h}$ before low slack water to $2 \mathrm{~h}$ before high slack water for the neap tide day with a frequency of $1 \mathrm{~h}$ (Figure 2b). The GOCI-retrieved TSM concentration was in a range of $11.92-40.5 \mathrm{~g} \cdot \mathrm{m}^{-3}$, which is in the expected range according to previous in situ TSM in 2009 (ranging from $15.45-53.83 \mathrm{~g} \cdot \mathrm{m}^{-3}$ ). The RMSE between in situ TSM and GOCI-retrieved TSM was $9.11 \mathrm{~g} \cdot \mathrm{m}^{-3}$, which is reasonably good considering the comparison was not exactly synchronized. The GOCI results retrieved from this algorithm also agreed with other studies in the YRE and Yellow Sea based on in situ data and results retrieved from other ocean colour satellites [22,41-43].
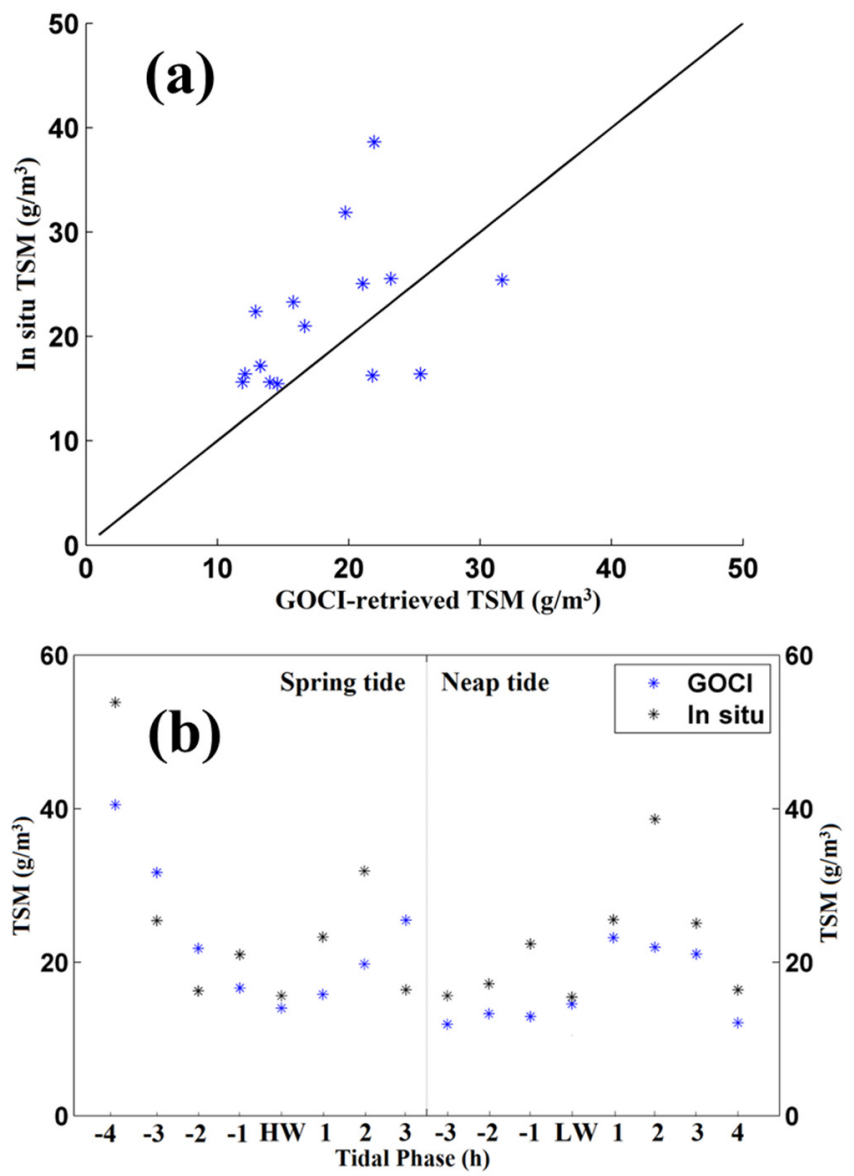

Figure 2. (a) Comparison between in situ total suspended particulate matter (TSM) in the upper layer at Y03 in August 2009 and the Geostationary Ocean Color Imager (GOCI)-retrieved TSM concentration at T1 in August 2014 and (b) same comparison under the tidal phase . "HW" and "LW" represent for high slack water and low slack water, respectively. "-" and "+" represent for hours "before" and "after", respectively 


\section{Results and Discussion}

\subsection{Diurnal Variation of TSM in the YRE}

TSM hourly maps in the YRE were derived from GOCI-retrieved $R_{r s}$ from cloud-free days throughout 2014, with Figures 3 and 4 showing the hourly TSM maps and corresponding tidal elevation for 3 April and 2 August of that year, respectively. The location of clouds varied hourly in those two days; however, the masked-out white patches nearshore did not all correspond to the cloud coverage. These invalid data nearshore correspond to tidal flats and reclamation area in the YRE (Figure 1), which prohibit the imager from observing valid ocean reflectance. In addition to tidal flats, the GOCI atmospheric correction is expected to fail in extremely turbid waters near the estuary $[2,18,19]$. Moreover, the cloud-masking threshold currently implemented by GDPS is too tight to reveal valid data in more turbid areas [16].
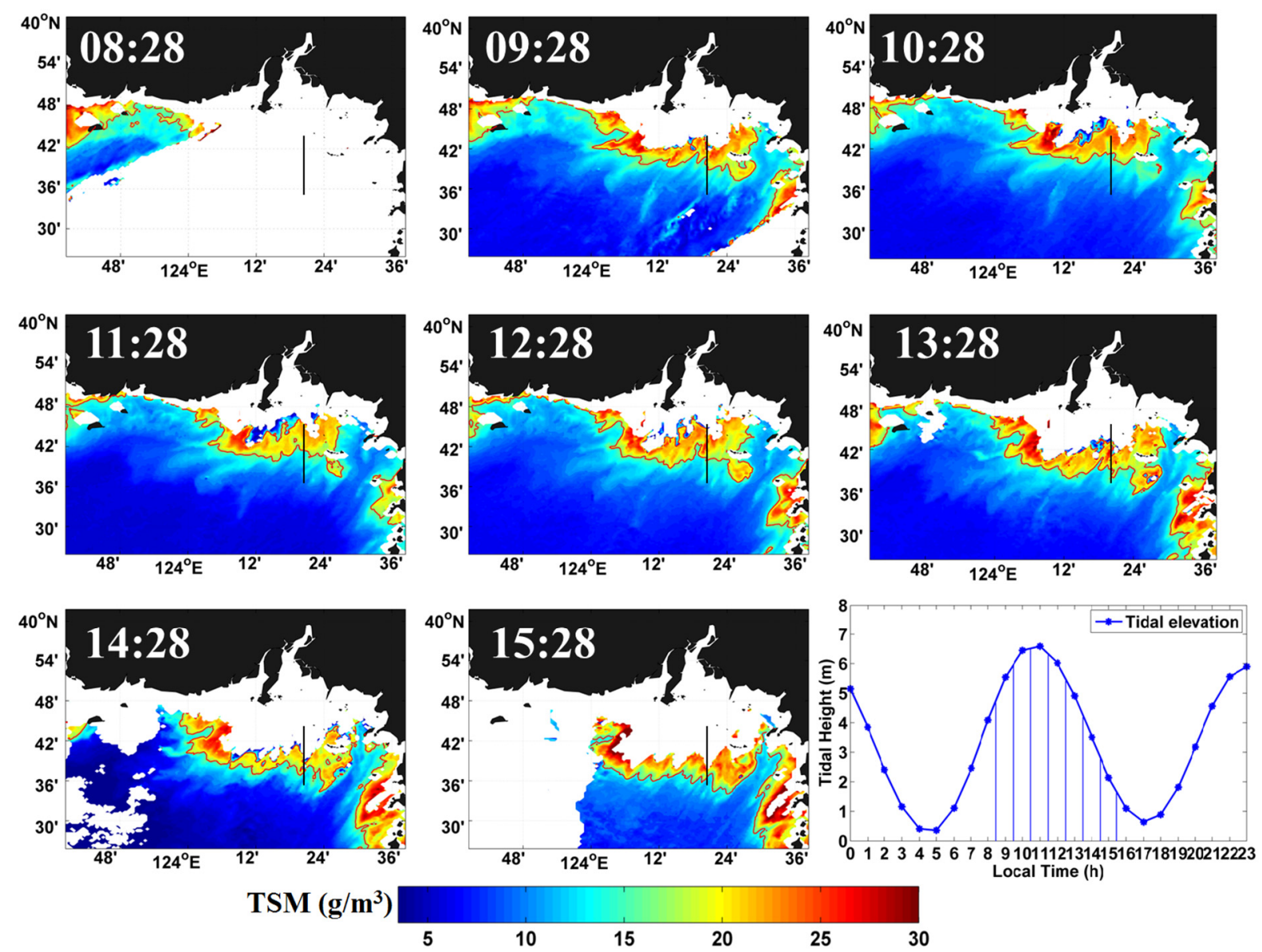

Figure 3. Hourly maps of GOCI-retrieved TSM from 08:28-15:28 (local time) in the Yalu River estuary on 3 April 2014. The graph shows the hourly tide elevation on the same day. Red lines demark the extent of the turbidity maxima zone ( $>15 \mathrm{~g} \cdot \mathrm{m}^{-3}$ TSM concentration). The black line represents the location of Section 1. 

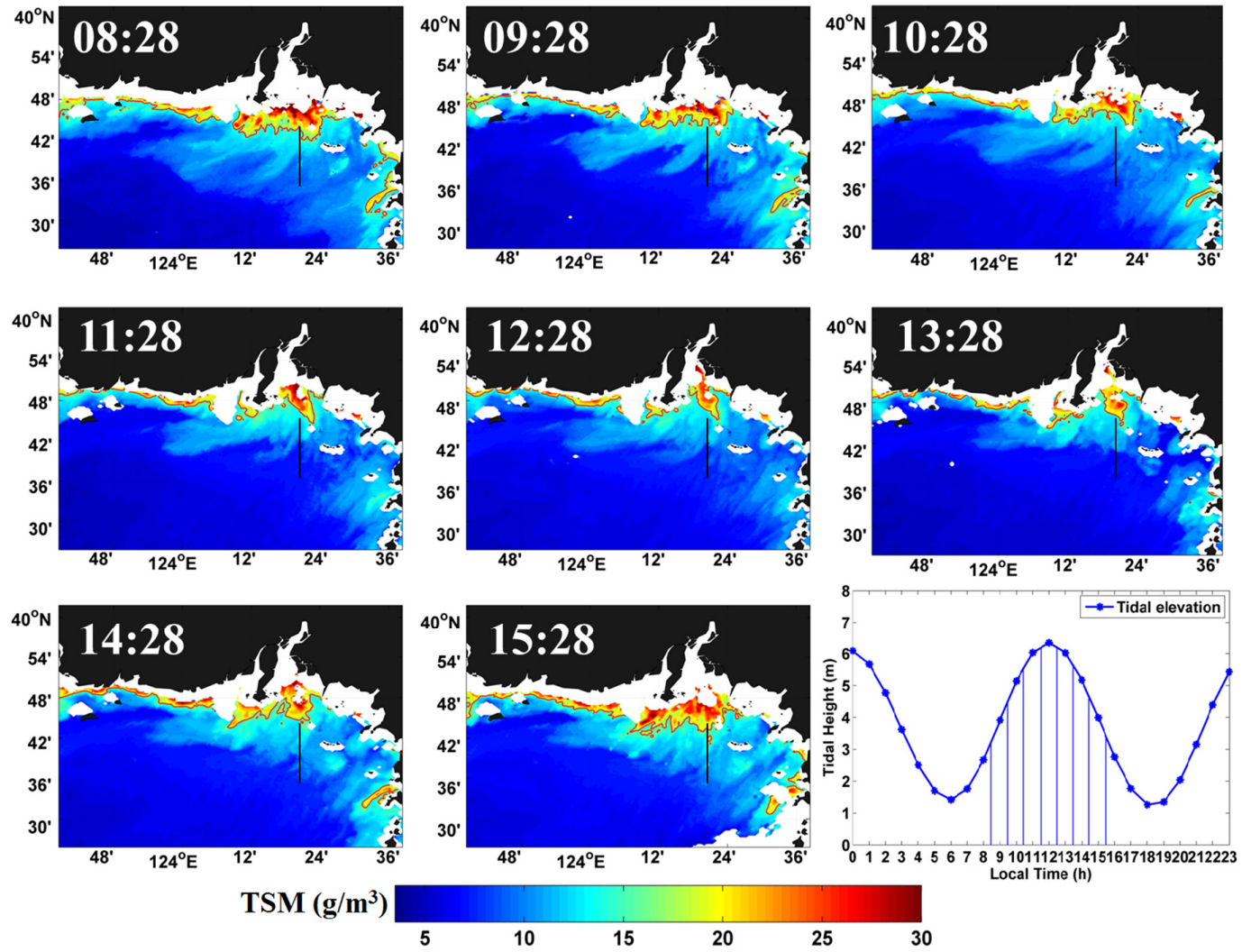

Figure 4. Hourly maps of GOCI-retrieved TSM from 08:28-15:28 (local time) in the Yalu River estuary on 2 August 2014. The graph shows the hourly tide elevation on the same day. Red lines demark the extent of the turbidity maxima zone (>15 $\mathrm{g} \cdot \mathrm{m}^{-3} \mathrm{TSM}$ concentration). The black line represents the location of Section 1.

Clear diurnal variation of TSM concentrations was exhibited in the YRE on these two days. The maximum TSM concentration ( $27 \mathrm{~g} \cdot \mathrm{m}^{-3}$ near the estuary) on 3 April 2014 was at 13:28 local time when the turbidity maxima (TM) zone (where surface TSM concentration was $>15 \mathrm{~g} \cdot \mathrm{m}^{-3}$ ) was broadly distributed (Figure 3); this corresponded to the time when a strong ebb tide took place (Figure 3). The minimum TSM value near the estuary was $<20 \mathrm{~g} \cdot \mathrm{m}^{-3}$ on that day and occurred at 11:28 when there was a high slack tide. TSM $>25 \mathrm{~g} \cdot \mathrm{m}^{-3}$ was seen in only a small and restricted area (red patches in Figure 3) at that time. On 2 August 2014 (Figure 4), the greatest TSM concentrations occurred, at 08:28 local time (about $2.5 \mathrm{~h}$ after low water) and 15:28 local time (around peak ebb time); the TSM concentration near the estuary reached about $25 \mathrm{~g} \cdot \mathrm{m}^{-3}$, which was the highest level for that day and was distributed across a relatively wide TM zone. TSM concentration was at its minimum value $\left(<20 \mathrm{~g} \cdot \mathrm{m}^{-3}\right.$ near the river mouth) at 12:28, which was one hour after high slack tide. The above results implied that diurnal variation of TSM had the same pattern with the maximum level occurring at peak flood/ebb tide and the minimum level being at slack tide, although the maps were at different times of the year.

To further investigate diurnal variability of TSM, several scenarios throughout the year under different tidal conditions were developed, which showed that TSM concentration changed closely with tidal elevation. The hourly section-averaged TSMs plotted in Figures 5-7 were the average values of TSM near the estuary without outliers (from $39^{\circ} 45^{\prime} \mathrm{N}-39^{\circ} 40^{\prime} \mathrm{N}$ ). The diurnal variations of wind speed and significant wave height were calculated based on data from ECMWF at UTC00h and UTC06h (local time 08:00 and 14:00). Annual-averaged water level at Donggang Station ("D" in Figure 1) in 2014 was $3.51 \mathrm{~m}$. According to cruises conducted in August 2009, the maximum depth-averaged current velocity for spring and neap tides at Station Y03 were 1.2 and $1.0 \mathrm{~m} \cdot \mathrm{s}^{-1}$, respectively. The results showed that 
the diurnal variations of wind and wave conditions were not significant. The mean daily difference of wind speed and significant wave height for those days were $0.91 \mathrm{~m} \cdot \mathrm{s}^{-1}$ and $0.24 \mathrm{~m}$, respectively. Thus, the daily averaged wind speed and significant wave height for those days are shown in Figures 5-7.
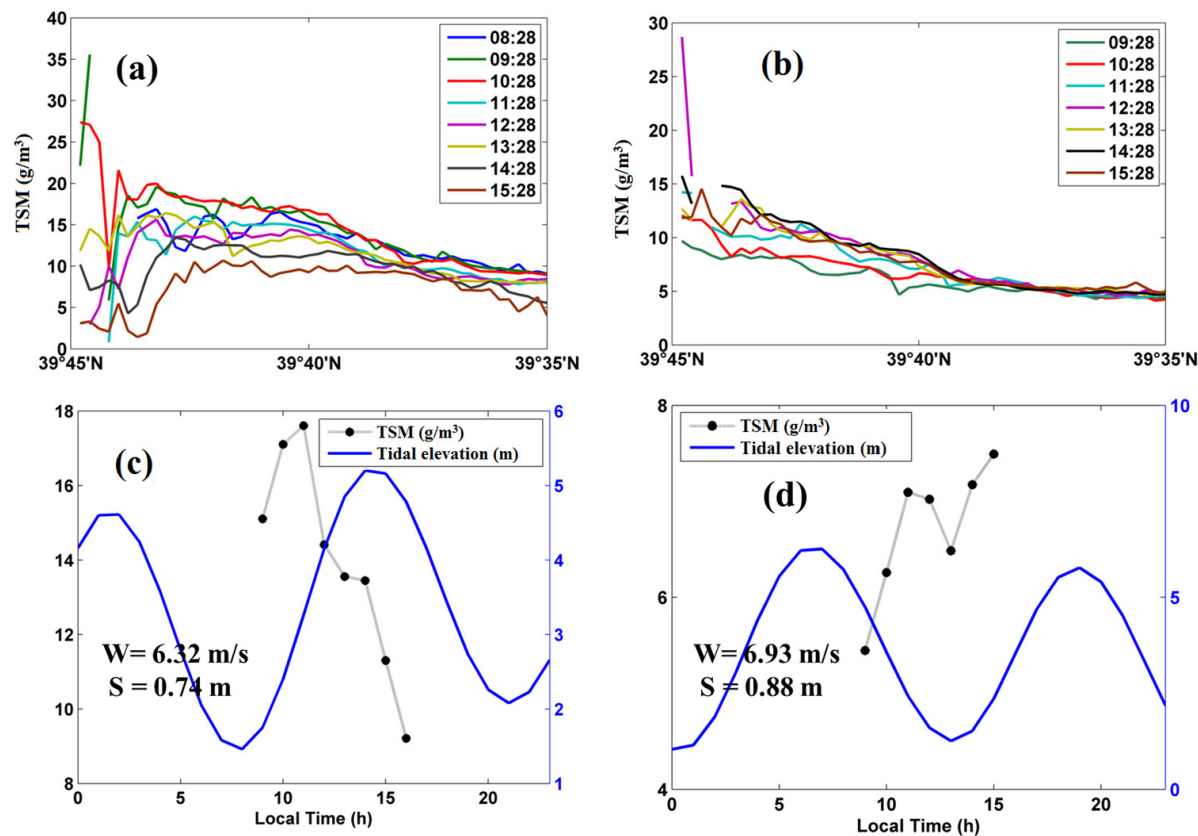

Figure 5. TSM variations at Section 1 from (a) 08:28-15:28 (local time) on 9 March 2014; (b) TSM variations at Section 1 from 09:28-15:28 (local time) on 26 May 2014, corresponding tidal elevation with section-averaged TSM concentration and conditions of wind and wave height (c) on 9 March 2014 and (d) on 26 May 2014. W and S represent wind speed and significant wave height, respectively.
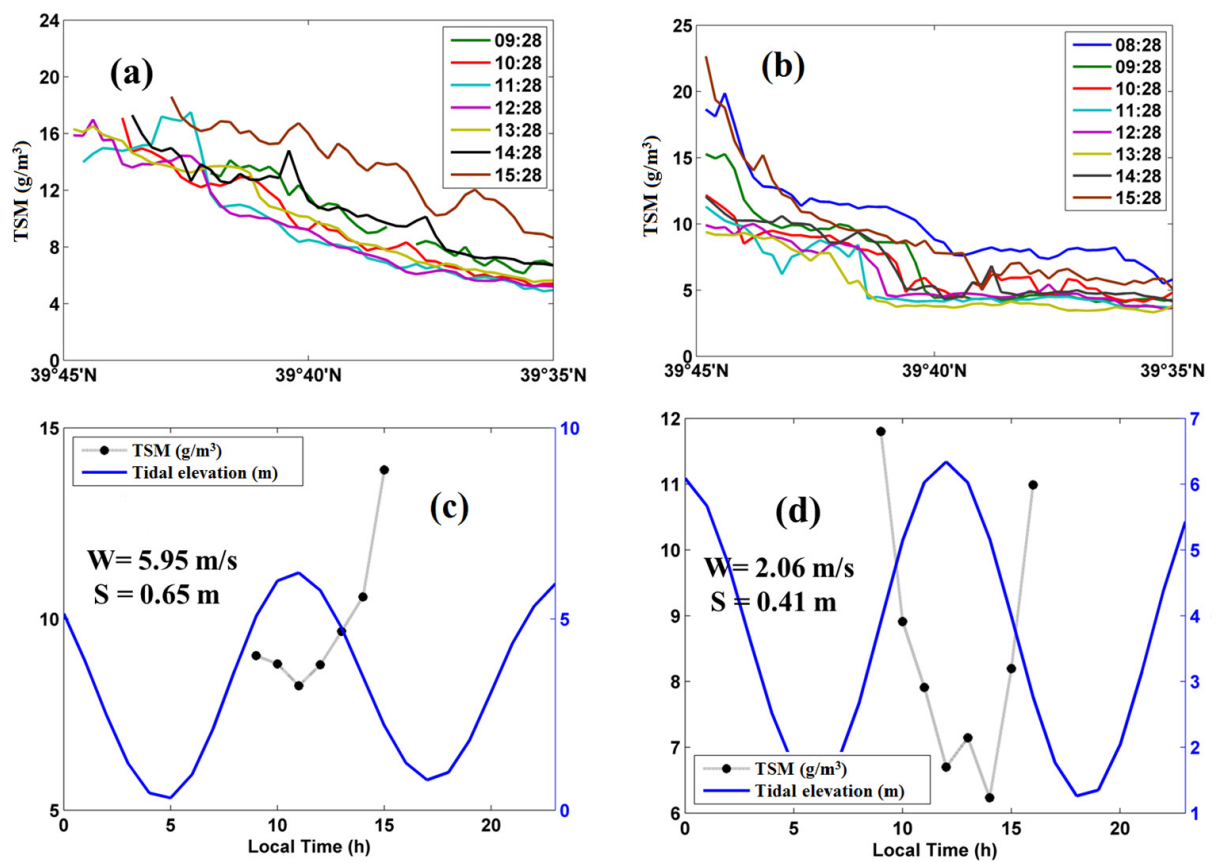

Figure 6. TSM variations at Section 1 from (a) 09:28-15:28 (local time) on 6 March 2014; (b) TSM variations at Section 1 from 08:28-15:28 (local time) on 2 August 2014, corresponding tidal elevation with section-averaged TSM concentration and conditions of wind and wave height (c) on 6 March 2014 and (d) on 2 August 2014. W and S represent wind speed and significant wave height, respectively. 

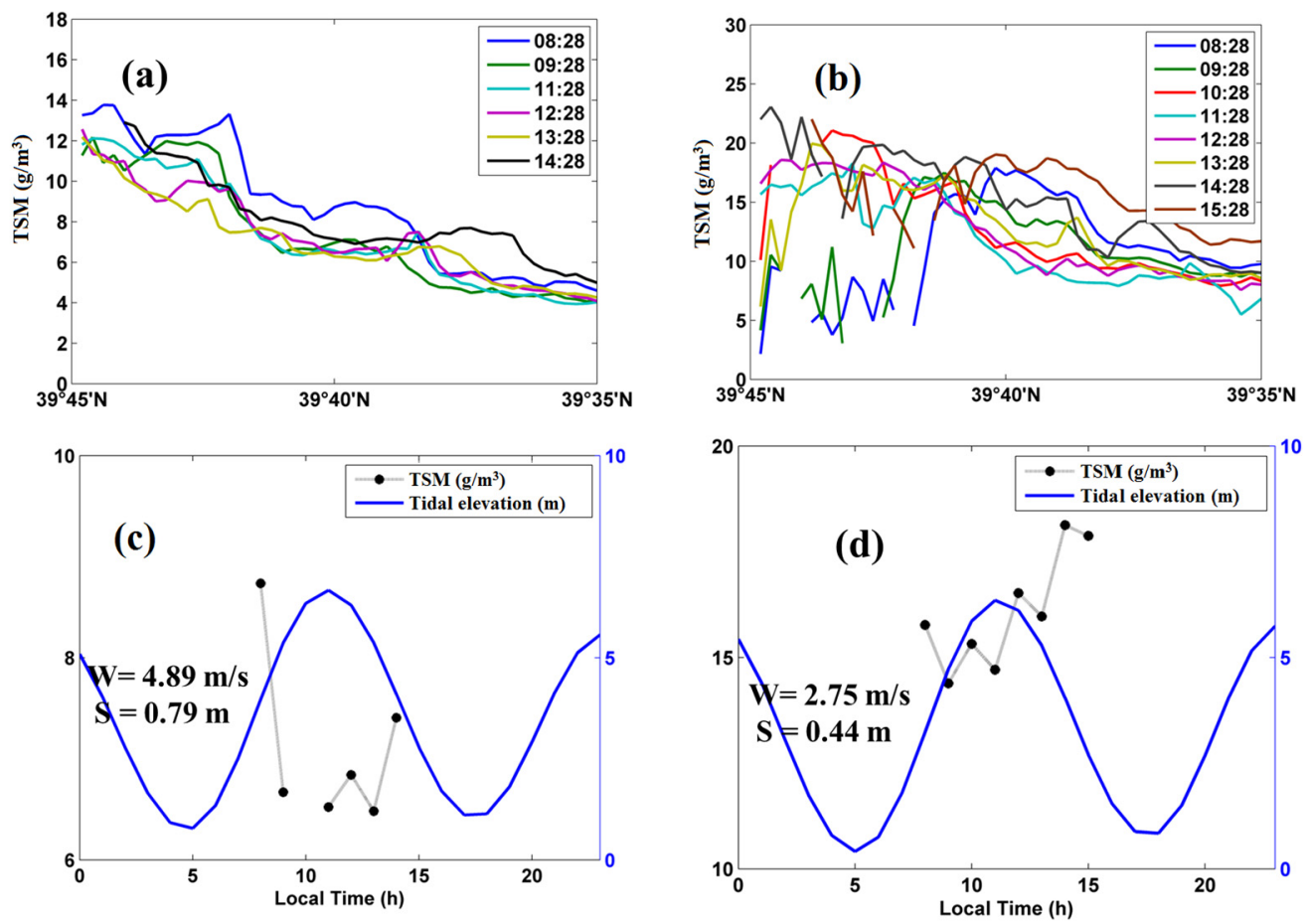

Figure 7. TSM variations at Section 1 from (a) 08:28-14:28 (local time) on 3 May 2014; (b) TSM variations at Section 1 from 09:28-15:28 (local time) on 21 March 2014, corresponding tidal elevation with section-averaged TSM concentration and conditions of wind and wave height (c) on 3 May 2014 and (d) on 21 March 2014. W and S represent wind speed and significant wave height, respectively.

TSM variations across Section 1 on 9 March (Figure 5a) were largely during a flood tide phase from low slack water (08:28 local time) to around an hour after high water (15:28 local time); TSM concentration near the estuary was around $15 \mathrm{~g} \cdot \mathrm{m}^{-3}$ at 08:28 and then increased to the highest level of that day at 10:28. After that, the TSM value declined with water level rising until an hour after high slack tide. For the case of ebb tide, TSM concentration on 26 May (Figure 5b) increased gradually during the whole ebb phase from 09:28-14:38 local time before slightly dropping at the end of the observation period (15:28 local time). The TSM value near the estuary was at its minimal value of $4 \mathrm{~g} \cdot \mathrm{m}^{-3}$ at 09:28 local time and at a maximum value of $8 \mathrm{~g} \cdot \mathrm{m}^{-3}$ at 14:28, regardless of several unstable values at 12:28.

Cases covering both flood and ebb tide phases are shown in Figure 6. The lower level of TSM can be identified at 11:28 and 12:28 local time on 6 March when the high slack tide occurred. The maximum value of TSM that day was around one hour after peak ebb tide (15:28 local time). For 2 August 2014 (Figure 6b), during the flood tide, TSM concentration was near the maximum value for the day at 8:28, then decreased as the water level rose, eventually reaching the lowest value at 13:28 after high water. Conversely, the TSM at Section 1 increased during the ebb tide, resulting in a second peak value at 15:28 local time.

In the case of 3 May 2014 (Figure 7a), and similar to the case of 2 August 2014, there were two high levels of TSM concentration occurring at 08:28 and 15:28, corresponding to the maximum ebb and flood currents, respectively. By contrast, TSM was at a lower level when the low slack tide occurred that day. On 21 March 2014 (Figure 7b), the lowest level of TSM was at 11:28 local time around the time that high slack water occurred. Interestingly, the TSM peak near the estuary showed a landward movement during flood tide and a seaward movement when the ebb tide occurred. This was probably due to the effect of horizontal advection of the TM zone, but this effect was not evident on the other days [44]. 
In general, TSM results across the study area showed a pattern with two peaks, corresponding to the maximum ebb and flood times, respectively. Although TSM results for an entire tidal cycle could not be obtained due to the temporal limitations of GOCI, a couple of inferences about TSM diurnal dynamics could be reached from the above results. At the onset of flood phases, strong tidal currents likely enhanced vertical mixing and thus reinforced the re-suspension process of fine sediments on the seabed. TSM concentration then reached its first high level before high water when these suspended sediments came to the surface. After that, parts of the suspended sediments were deposited when the flood currents decreased until high slack water, resulting in the decline of surface TSM. For the ebb tide phases, aside from the increase of tidal currents, the materials previously deposited were likely re-suspended again, inducing another peak of TSM three hours after high slack water. Such a pattern of the variation of TSM within a tidal cycle matches the findings of a previous sediment study in the YRE using field measurements [22]. It is noteworthy that in some cases, TSM peaks during flood phases were lower than those of ebb phases, showing some effect of horizontal advection of the TM zone on the TSM variation: horizontal advection of the turbid maxima zone nearshore induced by the ebb current produced a TSM peak in ebb phases higher than those in flood phases on those two days (Figures $6 \mathrm{a}$ and $7 \mathrm{~b}$ ). In summary, the results retrieved from GOCI implied that diurnal variations of surface TSM in the YRE were closely related to the phases of tidal currents during the period of observation, suggesting tides to be the dominant factor controlling TSM diurnal dynamics in this area. Surface TSM peaks in this estuary corresponded to the time when the strongest tidal currents occurred. Both the processes of tidal re-suspension and advection can be identified from these results. However, the sediment re-suspension process played a more important role because in most cases, the TSM value increased at peak flood time instead of decreasing over the entire flood phase. Therefore, TSM diurnal dynamics in the YRE appear to be mainly controlled by a tidal re-suspension process of fine-grained bed sediment.

\subsection{The Effect of Spring-Neap Tidal Cycle on Diurnal Variation of TSM in the YRE}

Previous studies using ocean sensor and model results have revealed that estuarine TSM dynamics can be strongly affected by fortnightly tides (the spring-neap tidal variations) [9,45-47]. According to field measurements from Huanggou Hydrological Station, the difference of tidal range between spring and neap tides in the YRE can be up to $3 \mathrm{~m}$. In addition, the magnitude of currents during spring tides can be more than twice those of neap tides, indicating that the effect of spring-neap tidal variations on hydrodynamics in the YRE is substantial.

To examine this effect, two dates that had minimal cloud coverage were chosen for analysis; maximum tidal ranges on 30 May 2014 (spring tide) and 8 June 2014 (neap tide) were $5.81 \mathrm{~m}$ and $2.92 \mathrm{~m}$, respectively. As Figure 8a,b revealed, the surface TSM concentration and its spatial extent throughout the estuary and adjacent areas on 30 May 2014 were substantially greater than that on 8 June 2014. On 30 May, the TSM concentration in the YRE reached up to $20 \mathrm{~g} \cdot \mathrm{m}^{-3}$ and was $>15 \mathrm{~g} \cdot \mathrm{m}^{-3}$ in many areas. The area of the TM zone was also extensive on 30 May 2014. Conversely, on 8 June 2014, aside from a small area downstream from the middle channel of the Yalu River, the TSM concentration was generally $<15 \mathrm{~g} \cdot \mathrm{m}^{-3}$, except a small area near the river entrance.

Figure $8 c, d$ map the standard deviation (SD, normalized by the number of valid pixels) of eight measurements on 30 May 2014 and 8 June 2014, respectively. The magnitude of TSM close to the estuary during the spring tide of 30 May 2014 fluctuated considerably, along with the relatively high tidal range (Figure 8c). On the other hand, TSM concentration near the open sea of the study area displayed small fluctuations due to the greater water depth. By contrast, for the neap tide of 8 June 2014 , only a few SD values in restricted areas were $>8 \mathrm{~g} \cdot \mathrm{m}^{-3}$, indicating that TSM near the estuary showed little fluctuation on that day (Figure $8 \mathrm{~d}$ ). This implies that a large tidal range results in large TSM fluctuations in a diurnal cycle. SD values of cloud-free days from March-June 2014 lent support to this conclusion (Table 1). 

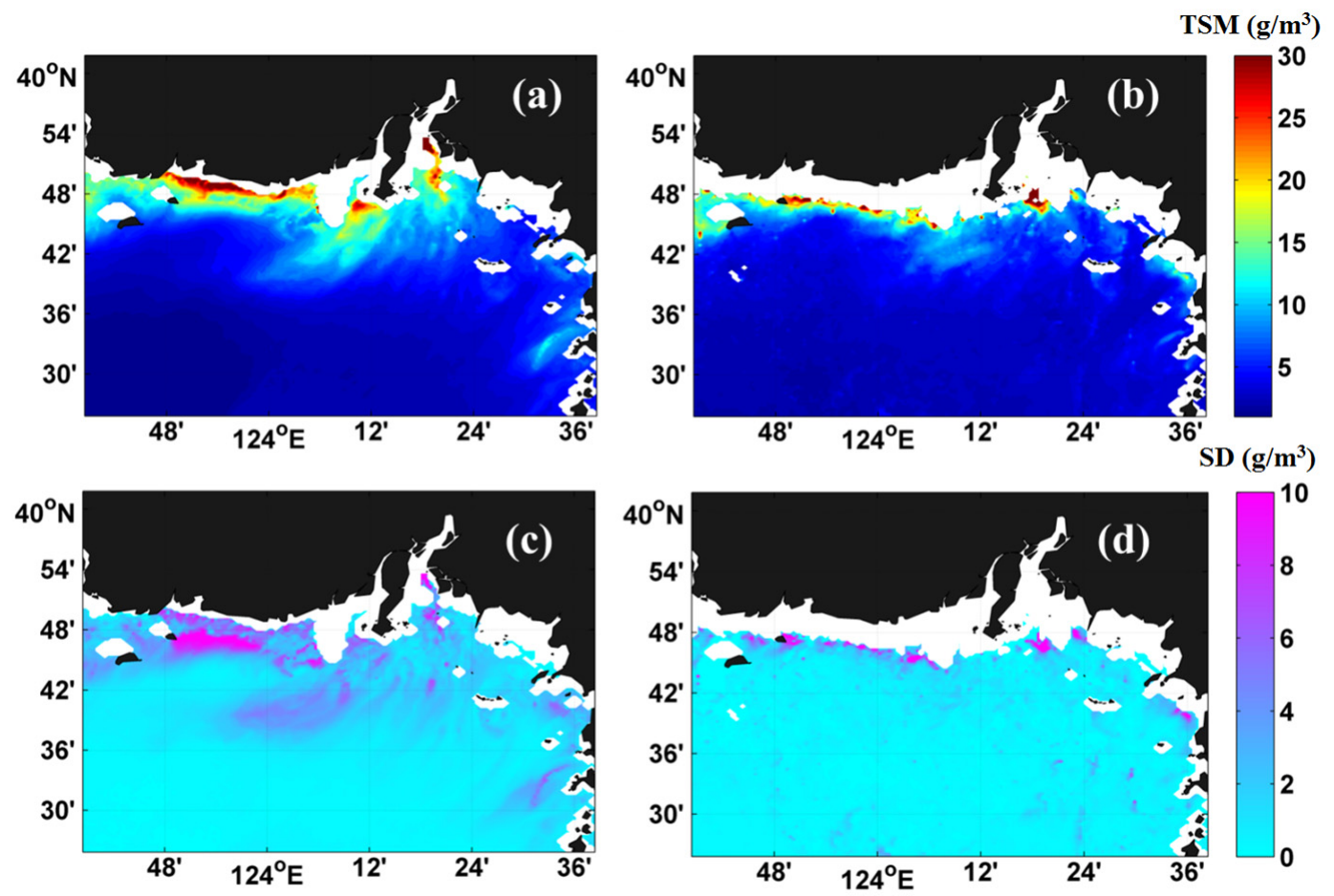

Figure 8. Spatial distributions of daily averaged TSM on (a) 30 May 2014 (spring tide) and (b) 8 June 2014 (neap tide). SD maps of TSM on (c) 30 May 2014 and (d) 8 June 2014.

Table 1. Wind speed, significant wave height, tidal range and SD values on scenarios from March-June 2014.

\begin{tabular}{ccccc}
\hline Date & 9 March & 30 March & 10 March & 21 March \\
\hline Wind Speed $(\mathrm{m} / \mathrm{s})$ & 6.32 & 5.63 & 3.05 & 2.75 \\
Significant Wave Height $(\mathrm{m})$ & 0.74 & 0.81 & 0.46 & 0.44 \\
Tidal Range $(\mathrm{m})$ & 3.74 & 5.82 & 3.02 & 4.35 \\
Standard Deviation $\left(\mathrm{g} / \mathrm{m}^{3}\right)$ & 1.29 & 2.54 & 0.75 & 1.93 \\
\hline Date & $\mathbf{3}$ May & $\mathbf{3 0}$ May & $\mathbf{8 ~ J u n e}$ & 14 June \\
\hline Wind Speed $(\mathrm{m} / \mathrm{s})$ & 4.89 & 2.57 & 4.06 & 1.07 \\
Significant Wave Height $(\mathrm{m})$ & 0.79 & 0.65 & 0.47 & 0.28 \\
Tidal Range $(\mathrm{m})$ & 3.89 & 5.00 & 2.72 & 6.34 \\
Standard Deviation $\left(\mathrm{g} / \mathrm{m}^{3}\right)$ & 0.96 & 1.40 & 0.66 & 1.13 \\
\hline
\end{tabular}

To eliminate the potential effects of wind and waves, several days in spring 2014 were selected as scenarios to show the effect of tidal range on daily SD of TSM (Table 1). Results on those days implied large fluctuations of TSM or large SD values generally corresponding to large tidal ranges. However, there was no strong relationship between wind or wave conditions and SD values in the results. For instance, the wind speed on 30 May 2014 and 8 June 2014 was $2.57 \mathrm{~m} \cdot \mathrm{s}^{-1}$ and $4.06 \mathrm{~m} \cdot \mathrm{s}^{-1}$, respectively. Although the wind speed on 30 May 2014 was weaker, the SD value on 30 May 2014 was larger than that on 8 June 2014. A similar relationship could be found on other days with strong/weak wind speed, but small/large SD due to the small/large tidal range on those days. Therefore, it could be concluded that TSM concentration varies considerably on days with a large tidal range.

As discussed above, large tidal currents can induce stronger vertical mixing and enhance the re-suspension of sediment. Thus, the high TSM concentration in the YRE on 30 May 2014 was probably caused by the large tidal current during spring tide. In contrast, weak tidal currents during neap tides minimized the sediment re-suspension process, which resulted in a low TSM level on 8 June 
2014. Furthermore, TSM results from a single day fluctuated substantially under strong tidal currents. Therefore, spring-neap tides can affect both TSM concentration and its magnitude of diurnal variations, with larger amplitudes observed during spring tides and smaller amplitudes during neap tides.

\subsection{Seasonal Variation of TSM in the YRE}

The spatial distribution of monthly mean TSM maps from January-December 2014 was shown in Figure 9. The variation of magnitude of TSM concentration over the one-year period was considerable, with a maximum value ranging from $30 \mathrm{~g} \cdot \mathrm{m}^{-3}$ in December 2014 to $8 \mathrm{~g} \cdot \mathrm{m}^{-3}$ in August 2014. The TM zone was generally located in near-coastal waters, especially in the estuary of the river (Figure 9). In winter, the TM zone expanded widely southward from the coast to the open sea. However, the edge of the TM zone was basically parallel to the coastline within a limited region in summer.
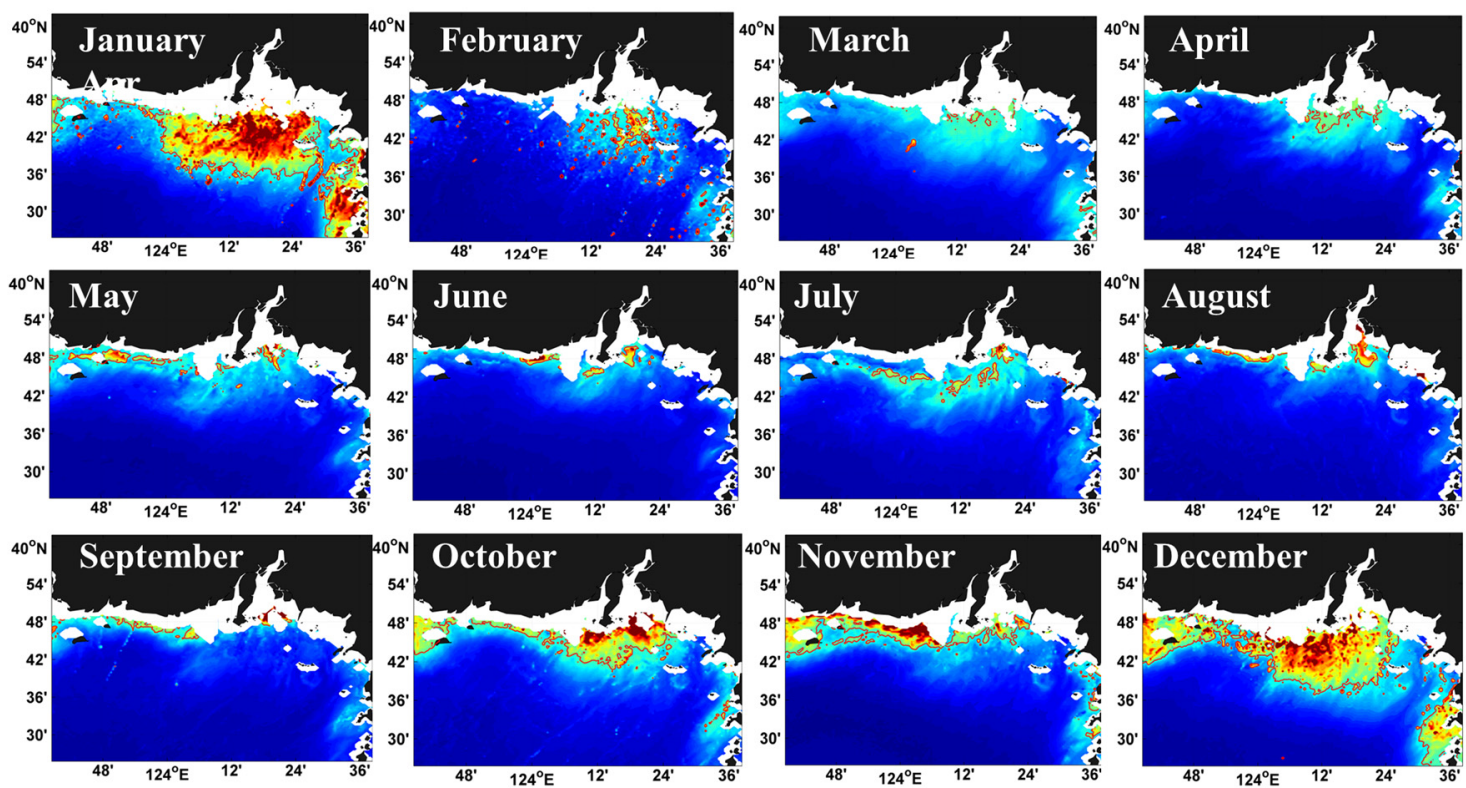

$\operatorname{TSM}\left(\mathrm{g} / \mathbf{m}^{3}\right)$

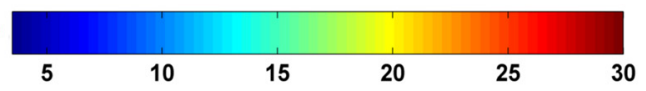

Figure 9. Monthly mean TSM maps retrieved from GOCI in the Yalu River estuary from January-December 2014. Red lines demark the extent of the turbidity maxima zone $\left(>15 \mathrm{~g} \cdot \mathrm{m}^{-3}\right.$ TSM concentration).

This seasonal pattern of TSM was also clearly seen in the daily averaged TSM value at P1, P4 and P5 from April 2011-December 2014 (Figure 10). TSM values at P4 ranged from about 3-45 $\mathrm{g} \cdot \mathrm{m}^{-3}$ during this period (Figure 10a) with pronounced seasonal variability; they reached a maximum in winter and significantly decreased by down to $80 \%$ in summer. TSM variations at P1 and P5 showed a similar pattern. 

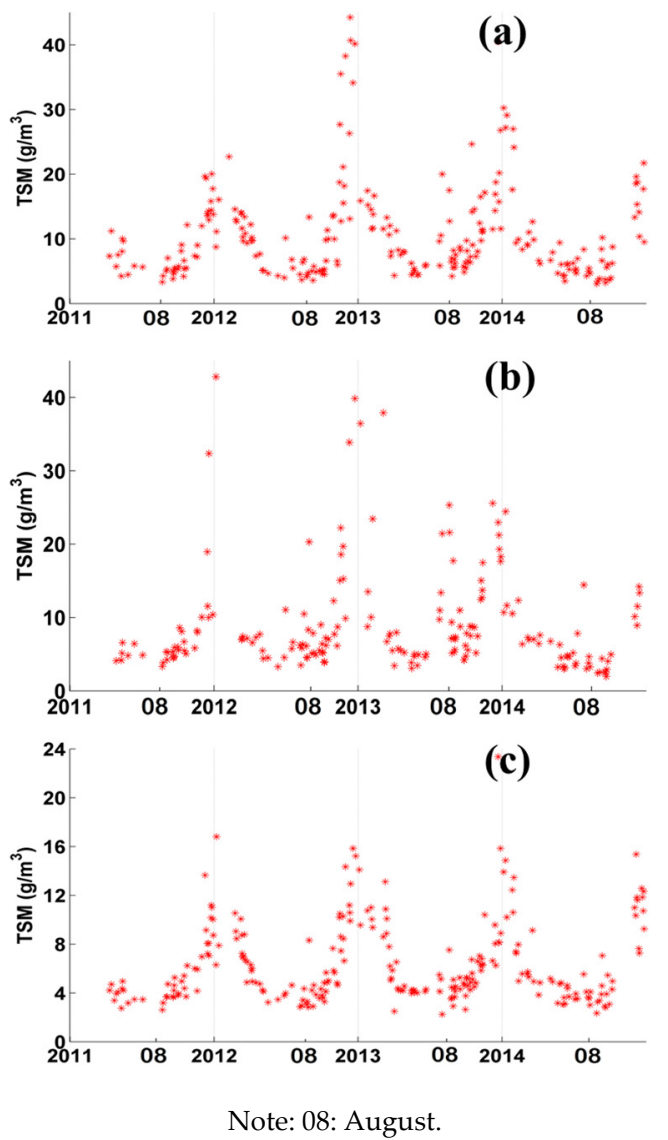

Figure 10. Daily averaged TSM retrieved from GOCI at (a) P1; (b) P4 and (c) P5 from April 2011-December 2014.

\subsection{Factors Controlling Seasonal Variability of TSM}

Numerous factors can affect seasonal variability of TSM, including tides, winds and river runoff $[2,48]$. Among them, river discharge is a major factor that can strongly affect the hydrodynamics of estuarine regions. Freshwater discharge of a river exerts an important influence on water circulation and material transport by the mixing process between fresh and salt water [49]. As described in Section 2, seasonal variability in the discharge of the YRE is substantial. To assess the effect of river discharge on TSM seasonal variability, comparisons between surface TSM concentrations in dry (April) and wet (August) seasons were made (Figure 11). The overall extent of the TM zone in April was considerably larger than August, as was the magnitude of TSM concentration (Figure 11a, cf. Figure 11b). The standard deviation (SD, normalized by the number of valid pixels) values of measurements on all cloud-free days in April (three days) and August (six days) 2014 are shown in Figures 11c and 11d. Extensive areas of high variability of TSM occurred in April compared to August, indicating different controlling factors between these two seasons. However, although water discharge and sediment load of the river were both greater in the wet than dry season, the TSM concentration in August was lower than April, indicating that river discharge was not a dominant factor controlling TSM seasonal variation in the study area in 2014.

It is noteworthy that TSM across Section 1 in 2013 displayed a different pattern from 2014 (Figure 12a, cf. Figure 12b), whereby areas close to the estuary had a higher value of TSM in August compared to April 2013, with the opposite occurring in 2014. The peak water discharge between 2011 and 2014 occurred in 2013 and was approximately three times greater than in 2014 (Figure 12c). This substantial discharge in 2013 likely induced the higher TSM concentration in August that year. 
However, it would only have affected areas close to the river mouth, as the TSM concentration further offshore in August 2013 was similar to April of that year.
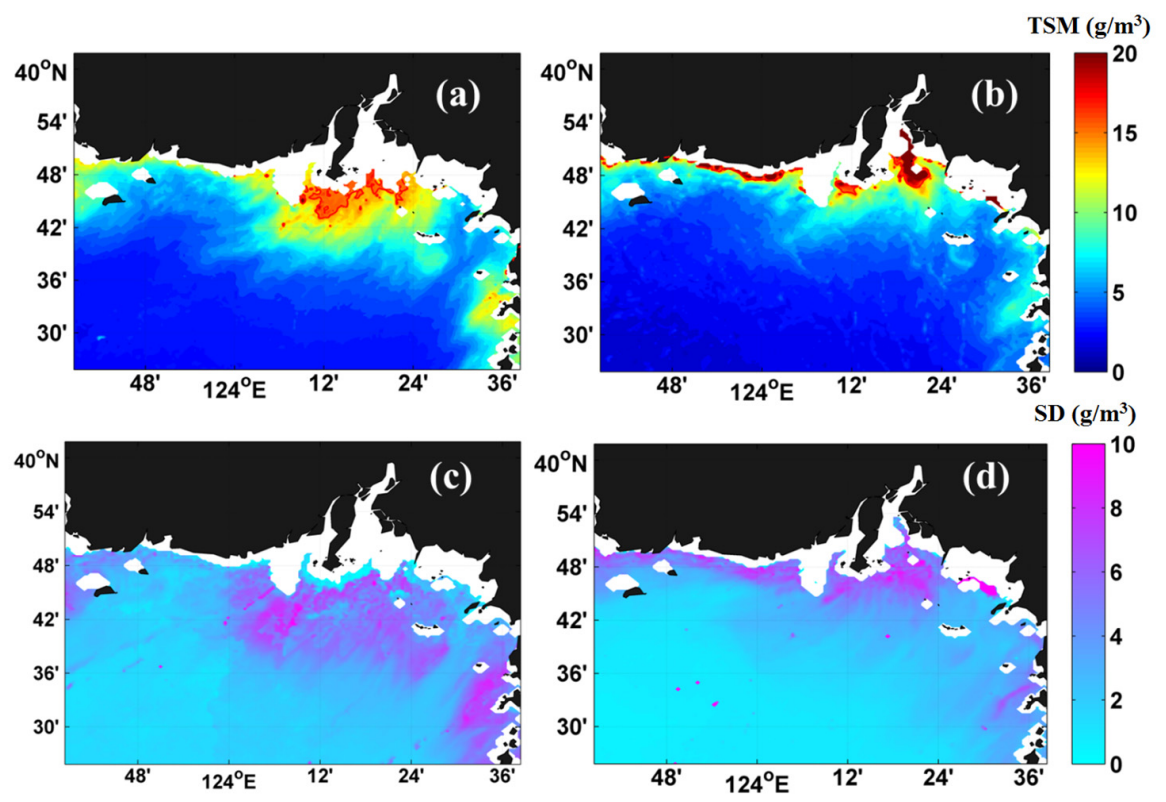

Figure 11. Spatial distributions of monthly mean TSM in (a) April 2014 (dry season) and (b) August 2014 (wet season). SD maps of TSM on cloud-free days in (c) April 2014 and (d) August 2014.
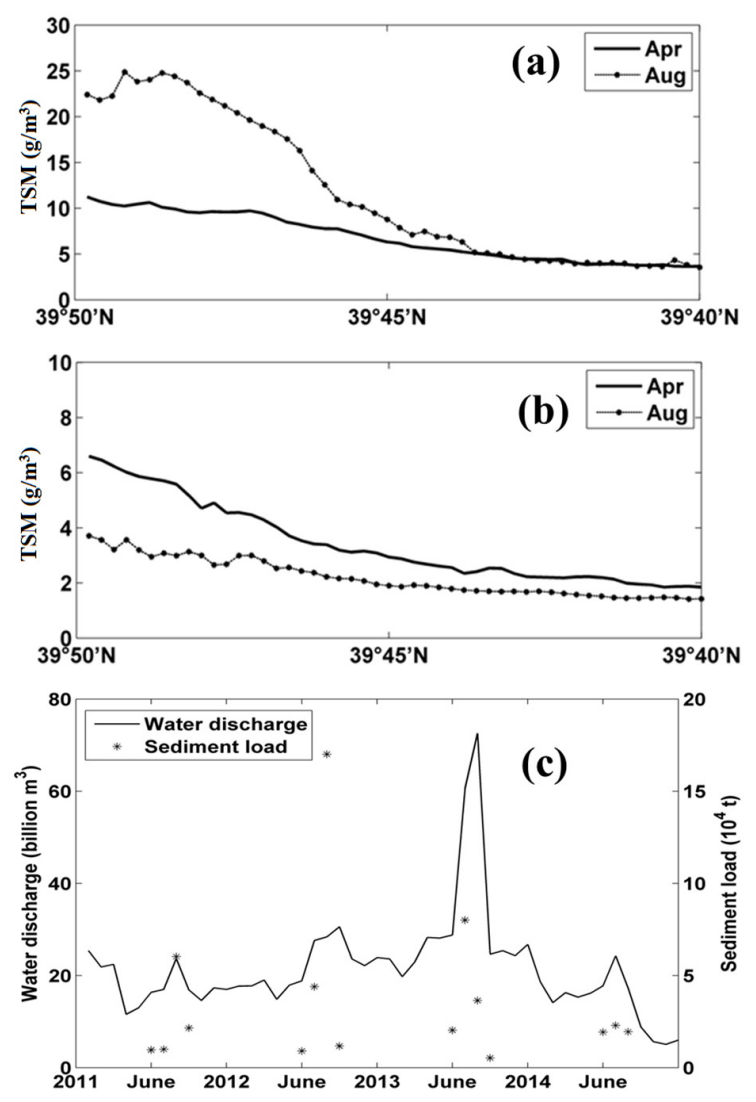

Figure 12. Monthly mean TSM across Section 1 in April and August of (a) 2013 and (b) 2014. (c) Monthly water discharge and sediment load in the wet season of the Yalu River from 2011-2014. 
Overall, river discharge did not play the key role in seasonal variability of TSM in the study area during the period of observation, but it appeared to affect TSM distribution in the inner estuarine area, especially during a significant flooding event. One possible reason for this is that the Yalu River has low turbidity as a consequence of sediment supply being reduced following dam construction in the river's upper reaches [50]. The paucity of sediments in the river has induced a significant decrease of terrigenous suspended materials in the YRE over the years [51]. Previous studies based on field measurements have revealed that the main source of suspended material in the YRE is caused by the re-suspension of fine-grained sediment on the seabed and suspended particles near the bottom layer [52]. Thus, despite peak river discharges occurring in the wet season, no higher TSM concentrations could be observed in the YRE at the same time.

According to field measurements in August 2009, vertical salinity gradients at Y03 were not significant in both spring and neap tide days in the wet season (Figure 13). Previous studies showed that the YRE is a well-mixed, macro-tidal estuary, even in wet seasons, due to the relatively small freshwater input [22,53]. The river plume could only affect a small area $2 \mathrm{~km}$ south of Station Y03 in wet seasons, which was masked out in most GOCI results [53].
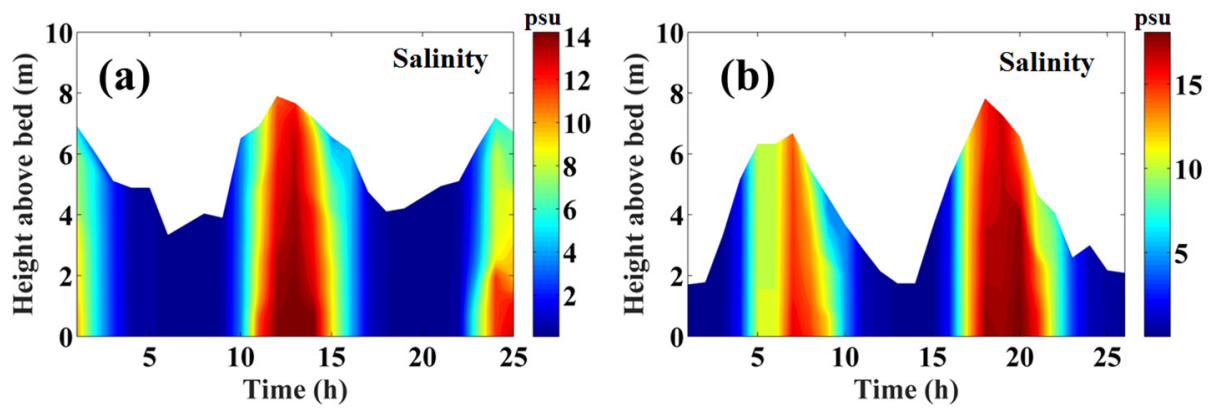

Figure 13. Vertical distribution of salinity at Station Y03 on (a) 15 August 2009 during neap tide and (b) 9 August 2009 during spring tide.

In other words, the YRE area is well-mixed in both spring and neap tides in wet season due to the relatively small water discharge of the Yalu River, and strong winds can easily enhance vertical mixing and sediment re-suspension, which can systematically affect TSM concentrations. According to measurements from Donggang Meteorological Station, there is a strong seasonal signal in the winds; they are mainly south to south-westerlies in spring and summer with an average speed $2.1 \mathrm{~m} \cdot \mathrm{s}^{-1}$, but become stronger northerlies with an average speed of $2.9 \mathrm{~m} \cdot \mathrm{s}^{-1}$ in winter. Wind-driven currents in the YRE area are relatively weak compared to tidal currents. The maximum velocity of tidal currents in the YRE is $1.5 \mathrm{~m} \cdot \mathrm{s}^{-1}$, yet that of surface residual currents (induced by wind, river discharge and topography) in this area is $0.24 \mathrm{~m} \cdot \mathrm{s}^{-1}$ [24]. Thus, the effect of surface wind currents on TSM seasonal variability is likely to be negligible. Henceforth, the discussion of the mechanisms of TSM seasonal variability focuses on the impact of wind waves induced by strong winds.

Although wave action is limited in the Northern Yellow Sea, it can be stronger when propagating into estuarine areas. Strong waves in coastal waters can increase the apparent bottom roughness, which presents a larger bottom stress and, in turn, eventually enhances the re-suspension of sediment [54]. Furthermore, the bottom substrate of the YRE is mainly fine sediment with a median particle diameter of $0.123-0.163 \mathrm{~mm}$ downstream from the river and $0.112 \mathrm{~mm}$ in the shallow water south of the YRE [20]. These fine sediments on the seabed can be easily brought to the surface by a re-suspension process due to the limited water depth. Such an effect of wind waves on sediment re-suspension has been reported in many other coastal areas throughout the world, including the northern Adriatic Sea [55], northern Jiangsu shoal-water [56], the Yangtze River estuary [57] and Hangzhou Bay [2].

Figure 14 shows the relationship between daily averaged GOCI-retrieved TSM concentrations at P4 and corresponding wind speed/significant wave height for all cloud-free days in 2014. Wave height 
had a strong positive linear relationship $\left(\mathrm{R}^{2}=0.76\right)$ with wind speed during this period. Although there were some outlying values, high wind speeds and large wave heights generally corresponded to high TSM concentrations. In addition, according to monthly-mean wind observations from the Donggang Meteorological Station in 2014 (Table 2), the wind speed in winter that year was greater than that of summer. Strong winds in winter generate large waves, which then enhance the re-suspension of fine sediments on the seabed; high TSM concentrations are thus induced at the surface in winter. By contrast, relatively weak winds in summer result in a lower TSM concentration in the region. These results implied that wind waves were a major factor controlling TSM seasonal variation in the YRE and its adjacent waters during the period of observation.

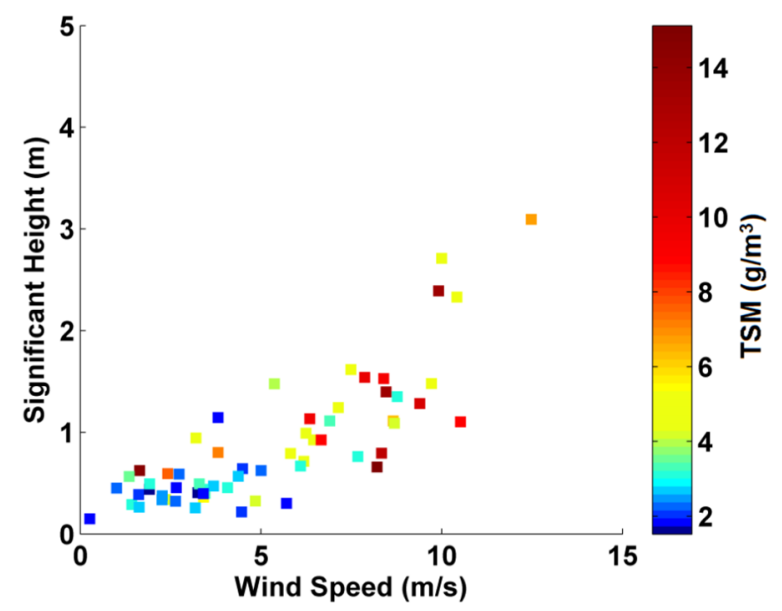

Figure 14. Relationship between area-averaged GOCI-retrieved daily averaged TSM concentration and corresponding wind speed/significant wave height for all cloud-free days at P4 in 2014.

Table 2. Monthly-mean wind speed and wind direction in 2014.

\begin{tabular}{ccccccc}
\hline Month & January & February & March & April & May & June \\
\hline Wind Speed $\left({\left.\mathrm{m} \cdot \mathrm{s}^{-1}\right)}^{2.1}\right.$ & 2.2 & 2.3 & 2.1 & 2.2 & 1.7 \\
Wind Direction & NE & NNE & NNW & SW & SW & SW \\
Month & Jul & Aug & Sep & Oct & Nov & Dec \\
Wind Speed $\left(\mathrm{m} \cdot \mathrm{s}^{-1}\right)$ & 1.7 & 1.6 & 1.8 & 2.1 & 1.9 & 2.3 \\
Wind Direction & WSW & ENE & ENE & ENE & ENE & ENE \\
\hline
\end{tabular}

Aside from the sediment re-suspension process enhanced by large wind waves, wind-driven residual currents may affect TSM variation by influencing the vertical mixing process. The strong northeast winds during winter in the offshore direction can enhance near-bed onshore residual currents and nearshore upwelling, whereas onshore southerlies in summer enhance near-bed offshore residual currents and nearshore down welling. These interacting with the horizontal salinity gradients can affect the vertical mixing of the water body, which influences TSM dynamics. However, given that this is a well-mixed estuary, as shown in Figure 13, this mechanism may not be significant in comparison with sediment resuspension driven by tides and waves in this region.

\section{Conclusions}

In the present study, GOCI data were used to retrieve the surface TSM concentrations in the YRE. We investigated TSM distribution and its variations over both diurnal and seasonal time scales.

The analysis of TSM diurnal variability in days with different tidal conditions provided the following insights. (1) There were usually two peaks of TSM in a tidal cycle that occurred 2-3 h after low and high slack tides, respectively; (2) Effects of both tidal re-suspension and advection 
on TSM diurnal variation can be identified. However, the sediment re-suspension process played a more dominant role in this variation. Surface TSM peaks in the YRE corresponded to the time when maximum tidal current velocity occurred, which suggested that TSM diurnal variation was mainly affected by sediment re-suspension due to tidal currents; (3) Accordingly, tidal action was the main factor driving the spatial and temporal diurnal variations of TSM, and spring-neap tides affected both TSM concentration and the magnitude of TSM diurnal variations in the YRE.

A comparison of TSM results in different seasons showed that there was clear seasonal variability of surface TSM in this area, with the highest level occurring in winter and the lowest in summer. The TM zone expanded offshore and had the maximum extent in winter. In contrast, the TM zone was limited in summer. Although discharge of the Yalu River was much higher in the wet season compared to the dry season, TSM concentration was significantly higher in the dry season. However, river discharge can affect the TSM seasonal distribution in the inner estuary of the YRE in a year with flooding events. Compared to river discharges, the seasonal action of wind waves was considered to be the main factor affecting TSM seasonal variation in the YRE. The relationship between daily averaged TSM concentration and wind speed/significant wave height suggested that very high TSM concentrations usually corresponded to strong wind waves. The seasonal variation of TSM caused by winds was maintained by the wave driven re-suspension process; due to the limited water depth of the study area, the highest TSM level in winter was caused by the intense re-suspension of bottom sediment induced by large wind waves. From the above results, we conclude that GOCI data are effective for estimating the diurnal and seasonal variability of TSM in the YRE. However, due to the limitation of the data coverage of GOCI and the complexity of hydrodynamics in the study area, the contribution of other possible mechanisms, such as wind-driven currents and flooding-induced stratification, to the sediment transport dynamics of the YRE region cannot be fully investigated. Therefore, further detailed study of TSM dynamics in the YRE based on field measurements and numerical modelling is needed to better understand sediment transport processes in the region.

Acknowledgments: This study was supported by Natural Science Foundation of China (No. 41271028 and No. 41576043), and we thank Korea Ocean Research \& Development Institute of the KOSC for providing us with the GOCI Level-1B data. We also thank the staff of Donggang Meteorological Station, Donggang Oceanographic Station and Huanggou Hydrological Station for supplying measurements about river discharges, tides, winds and wind waves in the study area; and to Julie Kesby (Research Officer, School of Physical, Environmental and Mathematical Science) for editorial advice. This is Publication No. 33 of the Sino-Australian Research Centre for Coastal Management.

Author Contributions: Zhixin Cheng is the primary author who processed the data and performed the experiments. Cheng also mapped and analysed the results. Xiao Hua Wang and David Paull conceived of and designed the experiments and provided guidance on the research. Wang and Paull also provided editorial input for this article. Jianhua Gao provided the field measurements in the study area and ideas about the discussion of the sediment transport process in the present study.

Conflicts of Interest: The authors declare no conflict of interest.

\section{References}

1. Neal, C.; Leeks, G.J.L.; Millward, G.E.; Harris, J.R.W.; Huthnance, J.M.; Rees, J.G. Land-ocean interaction: Processes, functioning and environmental management from a UK perspective, an introduction. Sci. Total Environ. 2003, 314-316, 3-11. [CrossRef]

2. He, X.Q.; Bai, Y.; Pan, D.L.; Huang, N.L.; Dong, X.; Chen, J.S.; Chen, C.-T.A.; Cui, Q.F. Using geostationary satellite ocean color data to map the diurnal dynamics of suspended particulate matter in coastal waters. Remote Sens. Environ. 2013, 133, 225-239. [CrossRef]

3. Miller, R.L.; McKee, B.A. Using MODIS Terra $250 \mathrm{~m}$ imagery to map concentrations of total suspended matter in coastal waters. Remote Sens. Environ. 2004, 93, 259-266. [CrossRef]

4. Choi, J.-K.; Park, Y.-J.; Lee, B.-L.; Eom, J.; Moon, J.-E.; Ryu, J.-H. Application of the Geostationary Ocean Color Imager (GOCI) to mapping the temporal dynamics of coastal water turbidity. Remote Sens. Environ. 2014, 146, 24-35. [CrossRef] 
5. Ilyina, T.; Pohlmannm, T.; Lammel, G.; Sündermann, J. A fate and transport ocean model for persistent organic pollutants and its application to the North Sea. J. Mar. Syst. 2006, 63, 1-19. [CrossRef]

6. Gao, S. Fine-grained sediment fluxes and cycling on continental shelves. Forum Young Sch. 21st Century 2000, 22, 73-76.

7. Tassan, S. Local algorithms using SeaWiFS data for the retrieval of phytoplankton, pigments, suspended sediment, and yellow substance in coastal waters. Appl. Opt. 1994, 33, 2369-2378. [CrossRef] [PubMed]

8. Zhang, M.; Tang, J.; Dong, J.; Song, Q.; Ding, J. Retrieval of total suspended matter concentration in the Yellow and East China Seas from MODIS imagery. Remote Sens. Environ. 2010, 114, 392-403. [CrossRef]

9. Shi, W.; Wang, M.; Jiang, L. Spring-neap tidal effects on satellite ocean color observations in the Bohai Sea, Yellow Sea, and East China Sea. J. Geophys. Res. 2011, 116. [CrossRef]

10. Wang, M.; Ahn, J.-H.; Jiang, L.; Shi, W.; Son, S.H.; Park, Y.J.; Ryu, J.H. Ocean color products from the Korean Geostationary Ocean Color Imager (GOCI). Opt. Express 2013, 21, 3835-3849. [CrossRef] [PubMed]

11. Liu, X.; Wang, M. River runoff effect on the suspended sediment property in the upper Chesapeake Bay using MODIS observations and ROMS simulations. J. Geophys. Res. Oceans 2014, 119. [CrossRef]

12. Choi, J.-K.; Park, Y.J.; Ahn, J.H.; Lim, H.-S.; Eom, J.; Ryu, J.-H. GOCI, the world's first geostationary ocean color observation satellite, for the monitoring of temporal variability in coastal water turbidity. J. Geophys. Res. 2012, 117. [CrossRef]

13. Ryu, J.-H.; Choi, J.K.; Eom, J.; Ahn, J.H. Temporal variation in Korean coastal waters using Geostationary Ocean Color Imager. J. Coast. Res. 2011, SI64, 1731-1735.

14. Bao, Y.; Tian, Q.J.; Chen, M. A weighted algorithm based on normalized mutual information for estimating the chlorophyll-a concentration in inland waters using Geostationary Ocean Color Imager (GOCI) data. Remote Sens. 2015, 7, 11731-11752. [CrossRef]

15. Ryu, J.-H.; Han, H.-J.; Cho, S.; Park, Y.-J.; Ahn, Y.H. Overview of Geostationary Ocean Color Imager (GOCI) and GOCI Data Processing System (GDPS). Ocean. Sci. J. 2012, 47, 223-233. [CrossRef]

16. Lou, X.L.; Hu, C.M. Diurnal changes of a harmful algal bloom in the East China Sea: Observations from GOCI. Remote Sens. Environ. 2014, 140, 562-572. [CrossRef]

17. Lee, B.R.; Park, Y.J.; Ahn, J.H. Improvement of atmospheric correction for extremely turbid waters using modified MUMM atmospheric correction algorithm. In Proceedings of the International Symposium on Remote Sensing, Ministry of Environment, Incheon, Korea, 10-12 October 2012.

18. Ruddick, K.; Vanhellemont, Q.; Yan, J.; Neukermans, G.; Wei, G.M.; Shang, S.L. Variability of suspended particulate matter in the Bohai Sea from the Geostationary Ocean Color Imager (GOCI). Ocean. Sci. 2012, 47, 331-345. [CrossRef]

19. Yang, H.; Choi, J.K.; Park, Y.J.; Han, H.J.; Ryu, J.H. Application of the Geostationary Ocean Color Imager (GOCI) to estimates of ocean surface currents. J. Geophys. Res. Oceans 2014, 119, 3988-4000. [CrossRef]

20. Cheng, P.; Gao, S.; Bokuniewicz, H. Net sediment transport patterns over the Northwestern Yellow Sea, based upon grain size trend analysis. Oceanol. Limnol. Sin. 2000, 31, 605-615.

21. Gao, J.-H.; Gao, S.; Dong, L.X.; Zhang, J. Sediment distribution and suspended sediment transport in Yalu River Estuary. Mar. Sci. Bull. 2003, 22, 27-33.

22. Yu, Q.; Wang, Y.; Gao, J.; Gao, S.; Flemming, B. Turbidity maximum formation in a well-mixed macrotidal estuary: The role of tidal pumping. J. Geophys. Res. Oceans 2014, 119, 7705-7724. [CrossRef]

23. Bai, F.L.; Gao, J.H.; Wang, Y.P.; Cheng, Y.; Lin, T.Y. Tidal characteristics at Yalu River Estuary. Mar. Sci. Bull. 2008, 27, 7-13.

24. State Oceanic Administration. Chinese harbours and embayments: Important estuaries. Ocean 1998, 14, 386-432. (In Chinese).

25. Seo, S.B.; Lim, H.S.; Ahn, S.I. Introduction to image proper-processing subsystem of Geostationary Ocean Color Imager (GOCI). Korean J. Remote Sens. 2010, 26, 167-173.

26. Gordon, H.R.; Wang, M. Retrieval of water-leaving radiance and aerosol optical thickness over the oceans with SeaWiFS: A preliminary algorithm. Appl. Opt. 1994, 33, 443-452. [CrossRef] [PubMed]

27. Wang, M.; Shi, W.; Jiang, L. Atmospheric correction using near-infrared bands for satellite ocean color data processing in the turbid western Pacific region. Opt. Express 2012, 20, 741-753. [CrossRef] [PubMed]

28. Doxaran, D.; Lamquin, N.; Park, Y.; Mazeran, C.; Ryu, J.H.; Wang, M.; Poteau, A. Retrieval of the seawater reflectance for suspended solids monitoring in the East China Sea using MODIS, MERIS and GOCI satellite data. Remote Sens. Environ. 2014, 146, 36-48. [CrossRef] 
29. Ruddick, K.; Ovidio, F.; Rijkeboer, M. Atmospheric correction of SeaWiFS imagery for turbid coastal and inland waters. Appl. Opt. 2000, 39, 897-912. [CrossRef] [PubMed]

30. Ahn, J.H.; Park, Y.J.; Ryu, J.H.; Lee, B.; Oh, I.S. Development of atmospheric correction algorithm for Geostationary Ocean Color Imager (GOCI). Ocean. Sci. J. 2012, 47, 247-259. [CrossRef]

31. Park, Y.-J. GOCI Level 2 Ocean. Color. Products (GDPS 1.3) Brief. Algorithm Description; Korean Ocean Satellite Center: Seoul, Korea, 2014.

32. Morel, A.; Gentili, B. Diffuse reflectance of oceanic waters, III, Implications of bidirectionality for the remote sensing problem. Appl. Opt. 1996, 35, 4850-4862. [CrossRef] [PubMed]

33. Morel, A.; Gentili, B.; Antoine, D. Assessing the Atmospheric and Marine Signal. from a Geostationary Orbit; COMS Ocean Data Processing System Development Project: Seoul, Korea, 2005.

34. Yu, X.; Du, J.B.; Gao, J.H.; Yang, Y.; Ran, L.J.; Li, F.X.; Liu, Y.; Cheng, Y. The influence of hydrodynamic characteristics on the distribution of chlorophy 11 concentration in the maximum turbidity of the Yalu Estuary. Acta. Oceanol. Sin. 2012, 34, 101-113.

35. Son, S.; Wang, M. Water properties in Chesapeake Bay from MODIS-Aqua measurements. Remote Sens. Environ. 2012, 123, 163-174. [CrossRef]

36. Gordon, H.R.; Brown, O.B.; Evans, R.H.; Brown, J.R.; Smith, R.C.; Baker, K.S.; Clark, D.K. A semi-analytical radiance model of ocean color. J. Geophys. Res. 1988, 93, 909-924.

37. Kong, J.L.; Sun, X.M.; Wong, D.W.; Chen, Y.; Yang, J.; Yan, Y.; Wang, L.X. A semi-analytical model for remote sensing retrieval of suspended sediment concentration in the gulf of Bohai, China. Remote Sens. 2015, 7, 5373-5397. [CrossRef]

38. Volpe, V.; Silvestri, S.; Marani, M. Remote sensing retrieval of suspended sediment concentration in shallow waters. Remote Sens. Environ. 2011, 15, 44-54. [CrossRef]

39. Nechad, B.; Ruddick, K.G.; Park, Y. Calibration and validation of a generic multisensor algorithm for mapping of total suspended matter in turbid waters. Remote Sens. Environ. 2010, 114, 854-866. [CrossRef]

40. Yu, X.L. Study on Retrieval of Sediment Concentration in Bo and Yellow Sea and Imputation of Missing Value Based on GOCI. Master's Thesis, Ocean University of China, Qingdao, China, 2013.

41. Pang, C.; Yu, W.; Yang, Y.; Han, D. An improved method for evaluating the seasonal variability of total suspended sediment flux field in the Yellow and East China Seas. Int. J. Sediment. Res. 2011, 26, 1-14. [CrossRef]

42. Shi, W.; Wang, M. Satellite views of the Bohai Sea, Yellow Sea, and East China Sea. Prog. Oceanogr. 2012, 104, 30-45. [CrossRef]

43. Chen, J.; Quan, W.; Cui, T.; Song, Q. Estimation of total suspended matter concentration from MODIS data using a neural network model in the China eastern coastal zone. Estuar. Coast. Shelf Sci. 2015, 155, 104-113. [CrossRef]

44. Hu, Z.F.; Pan, D.L.; He, X.Q.; Bai, Y. Diurnal variability of turbidity fronts observed by geostationary satellite ocean color remote sensing. Remote Sens. 2016, 8, 147. [CrossRef]

45. Vaz, J.; Mateus, M.; Dias, J.M. Semidiurnal and spring-neap variations in the Tagus Estuary: Application of a process-oriented hydro-biogeochemical model. J. Coast. Res. 2011, SI64, 1619-1623.

46. Blanton, J.O.; Seim, H.; Alexander, C.; Amft, J.; Kineke, G. Transport of salt and suspended sediments in a curving channel of a coastal plain estuary: Satilla River, GA. Estuar. Coast. Shelf Sci. 2003, 57, 993-1006. [CrossRef]

47. Song, D.H.; Wang, X.H. Suspended sediment transport in the Deepwater Navigation Channel, Yangtze River Estuary, China, in the dry season 2009: 2. Numerical simulations. J. Geophys. Res. Oceans 2013, 118, 5568-5590. [CrossRef]

48. Yu, J. Seasonal Distribution and Variation of Sediments in Yellow Sea. Master's Thesis, Ocean University of China, Qingdao, China, 2012.

49. Bai, Y.; He, X.; Pan, D.; Chen, C.-T.A.; Kang, Y.; Chen, X.; Cai, W.-J. Summertime Changjiang River plume variation during 1998-2010. J. Geophys. Res. Oceans 2014, 119, 6238-6257. [CrossRef]

50. Cheng, Y.; Bi, L.X. Primary character and motive change of shallow beach in Yalu River mouth. J. Sediment. Res. 2002, 3, 59-63.

51. Gao, J.-H.; Li, J.; Wang, H.; Bai, F.-L.; Cheng, Y.; Wang, Y.-P. Rapid changes of sediment dynamic processes in Yalu River Estuary under anthropogenic impacts. Int. J. Sediment. Res. 2012, 27, 37-49. [CrossRef] 
52. Gao, J.-H.; Gao, S.; Cheng, Y.; Dong, L.; Zhang, J. Formation of turbidity maxima in the Yalu River Estuary, China. J. Coast. Res. 2004, 43, 134-146.

53. Gao, J.H.; Gao, S.; Cheng, Y.; Dong, L.; Zhang, J. Sediment transport in Yalu river estuary. Chin. Geogr. Sci. 2003, 13, 157-163. [CrossRef]

54. Wang, X.H.; Pinardi, N. Modeling the dynamics of sediment transport and resuspension in the Northern Adriatic Sea. J. Geophys. Res. 2002, 107, 18:1-18:23. [CrossRef]

55. Wang, X.H.; Pinardi, N.; Malacic, V. Sediment transport and resuspension due to combined motion of wave and current in the northern Adriatic Sea during a Bora event in January 2001: A numerical modelling study. Cont. Shelf Res. 2007, 27, 613-633. [CrossRef]

56. Wang, X.H.; Qiao, F.L.; Lu, J.; Gong, F. The turbidity maxima of the northern Jiangsu shoal-water in the Yellow Sea, China. Estuar. Coast. Shelf Sci. 2011, 93, 201-211. [CrossRef]

57. Song, D.H.; Wang, X.H.; Cao, Z.; Guan, W. Suspended sediment transport in the deepwater navigation channel, Yangtze River Estuary, China, in the dry season 2009: 1. Observations over spring and neap tidal cycles. J. Geophys. Res. Oceans 2013, 118, 5555-5567. [CrossRef]

(C) 2016 by the authors; licensee MDPI, Basel, Switzerland. This article is an open access article distributed under the terms and conditions of the Creative Commons by Attribution (CC-BY) license (http:/ / creativecommons.org/licenses/by/4.0/). 